\title{
Modelling of Global Solar Radiation on Horizontal Surfaces for Mersin City
}

\author{
R. Kulcu, A. Suslu, C. Cihanalp, and D. Yilmaz
}

\begin{abstract}
Turkey is rich in solar energy potential due to its geographical location. Turkey's average annual sunshine duration is 2737 hours and the solar energy potential is $\mathbf{1 5 2 7}$ $\mathrm{kWh} / \mathrm{m}^{2}$ year. The major solar energy regions are South Eastern Anatolia Region and the Mediterranean regions in Turkey. In this context, Mersin province is located in the provinces of maximum solar radiation in Turkey.

Calculations of all the factors affecting the solar radiation from the atmosphere to the earth; creates a huge workload and the results cannot be obtained with sufficient accuracy. Therefore calculating the solar radiation coming to the earth models have been developed. In this study, the models for the prediction of solar radiation for Mersin city were evaluated using measured solar radiation data. Statistical aspects compliance of studied models were tested and validated which models the closest predicting to measured value.
\end{abstract}

Index Terms-Mersin, modelling of solar radiations, solar energy, solar radiation calculations.

\section{INTRODUCTION}

Energy is essential input of socio-economic prosperity and forward-looking development of today's technology. Therefore, region and country based energy policies and alternative strategies are developing in order to provide adequate, reliable and least damaging to the environment. This matter has a different position and property in Turkey. Turkey is dependent on importation for energy at a rate exceeding $70 \%$. This rate is increasing day by day. Therefore, government and the community have to apply some special policy and specify behavior pattern. Therefore, government and the community have to requires apply some special policies and behavior pattern [1]. While the gap between Turkey's energy production and consumption has been increasing from 1990 to 2004, in the later years of 2010 Turkey's energy production has provided just \%28-30 of our consumption. While Turkey's energy production is 34,47 MTEP in 2012, energy demand is 121 MTEP level in the same year [1]. Renewable energy sources aren't imported therefore it's national and reliable energy sources. Also these energy sources aren't run out and not produce exhaust and greenhouse gases emissions unlike conventional energy sources. The potentials of Renewable energy sources of Turkey showed in Table I.

Manuscript received July 9, 2015; revised December 22, 2015. This work was supported in part by the Suleyman Demirel University Faculty of Agriculture Department of Agricultural Machinery and Technology Engineering.

The authors are with the Department of Agricultural Machinery and Technology Engineering, Faculty of Agriculture, Suleyman Demirel University, Turkey (e-mail: recepkulcu@sdu.edu.tr, mail@ahmetsuslu.com, cihannurcihanalp@hotmail.com,denizyilmaz@sdu.edu.tr).
TABLE I: RENEWABLE ENERGy POTENTIALS OF TURKEy [2]

\begin{tabular}{lllll}
\hline \hline $\begin{array}{l}\text { Renewable } \\
\text { Energy } \\
\text { Source }\end{array}$ & Specify & $\begin{array}{l}\text { Natural } \\
\text { Potentials }\end{array}$ & $\begin{array}{l}\text { Technical } \\
\text { Potentials }\end{array}$ & $\begin{array}{l}\text { Economical } \\
\text { Potentials }\end{array}$ \\
\hline Solar Energy & $\begin{array}{l}\text { Electricity } \\
\text { (TWh/year) }\end{array}$ & 977000 & 6105 & 305 \\
\cline { 2 - 5 } & $\begin{array}{l}\text { Thermal } \\
\text { (MTEP/year) }\end{array}$ & 80000 & 500 & 25 \\
\hline $\begin{array}{l}\text { Hydro } \\
\text { Energy }\end{array}$ & $\begin{array}{l}\text { Electricity } \\
\text { (TWh/year) }\end{array}$ & 433 & 216 & 127.4 \\
\hline Wind Energy & $\begin{array}{l}\text { Electricity } \\
\text { (TWh/year) }\end{array}$ & 400 & 110 & 50 \\
\hline Wave energy & $\begin{array}{l}\text { Electricity } \\
\text { (TWh/year) }\end{array}$ & 150 & 18 & - \\
\hline Geothermal & $\begin{array}{l}\text { Thermal } \\
\text { Energy }\end{array}$ & 31500 & 7500 & 2843 \\
\hline & $\begin{array}{l}\text { Classical } \\
\text { (MTEP/year) }\end{array}$ & 30 & 10 & 7 \\
\hline \hline & $\begin{array}{l}\text { Modern } \\
\text { (MTEP/year) }\end{array}$ & 90 & 40 & 25 \\
\hline \hline
\end{tabular}

The solar energy has the feature of widespread more easily as to the other renewable energy sources with reasons such as its potential, its ease of use, its hygiene, being renewable and being eco-friendly. The factor of that it has height of setup costs, low productivity, marginal capacity according to the other energy sources and that being solved some similar technological and economic difficulties will make the solar energy more eligible in the future. Turkey is involved in sunbelt by geographical position; the utilization potential from the solar energy is at a size which needs to be examined importantly for its all regions apart from Eastern Black Sea. According to Solar Energy Potential Atlas of Turkey prepared by General Directorate of Renewable Energy, that annual average sunshine duration is 2373 hours ( 7,5 hours daily) and that total solar energy coming annually is $1527 \mathrm{kWh} / \mathrm{m}^{2}$ years $\left(4,2 \mathrm{kWh} / \mathrm{m}^{2}\right.$ daily) had been determined. An atlas indicating the solar energy distribution of our country within the context of the project of Solar Energy Potential Atlas had been created. The general image of this atlas has been shown in Fig. $1[3]$.

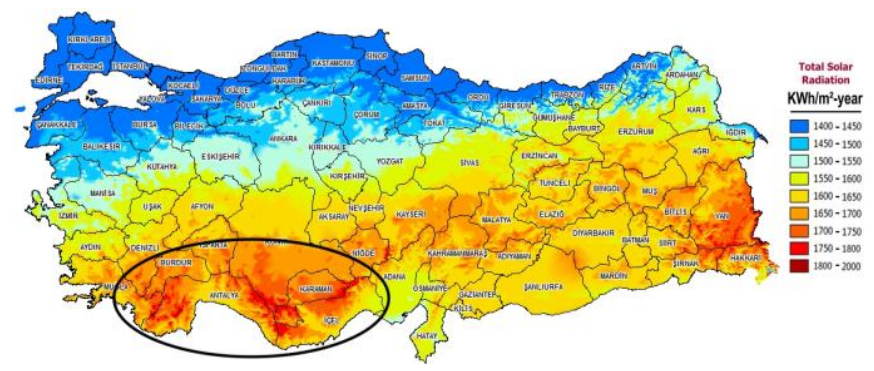

Fig. 1. Solar energy potential maps of Turkey. 
In Turkey, it is benefited from the solar energy in the field of hot-water generating, power generation, greenhouse heating, drying of agricultural products and heating buildings.

Design of systems that the solar energy is used and that the solar radiation coming to earth is known as a significant factor for determining its productivity. Datum of the solar radiation coming to earth (momentarily, hourly, daily) could be calculated by being measured with the solar radiation measuring device at meteorological stations or with assistance of mathematical correlations. Aim of the solar radiation calculations is to provide being calculated amount of the solar energy coming to a determinate coordinate between the desired dates. The amount of the solar energy coming to out of atmosphere could be calculated in high accuracy since there are very few factors affecting the radiation between sun and earth. Yet, being calculated of part reaching to earth of the radiation out of atmosphere is quite hard, and the models that make a prediction on calculations have been used. The models being developed show an alteration according to resource of datum which researcher used and coordinate that made measurement. Therefore, abilities of prediction have been on the wane in the case of that the same models are used and that coefficients used in the models are used at different geographical coordinates [4]. In this study, on conditions of Mersin the models have been semtinized to the end that relationships between the radiation coming to out of atmosphere and global monthly average daily radiation are determined and estimated. In the study, calculations have made by being six models taking part in literature, and it has been tried to state which model made more succeeded prediction by being compared datum obtained from the models with measured values. The models used within the context of the study as variable; have used values of sunshine duration, day length hour angle.

\section{MATERIAL AND METHODS}

Mersin City is located between $36-37^{\circ}$ North latitude and $33-35^{\circ}$ East longitude. Mersin City and around have temperate subtropical climate. Weather conditions is hot and too humidity in the summer months. Average weather temperature and humidity are $28^{\circ} \mathrm{C}$ and $88 \%$, respectively in summer months. In winter months average weather temperature is $16^{\circ} \mathrm{C}$ and rainy. Mersin City is the hottest city of Turkey and Europe.

In this study target to modeling of global solar radiation on horizontal surfaces for Mersin City using extraterrestrial radiation on a horizontal surface were evaluated. Calculations performed in two stages. At stage one extraterrestrial radiation on a horizontal surface in Mersin City were calculated. At stage two six models predicted global solar radiation on horizontal surfaces for Mersin City were evaluated. Predicted values were compared with measured values (1968-2004) by Turkish State Meteorological Service.

\section{A. Calculation of Extraterrestrial Radiation on a Horizontal Surface of Mersin City}

H0 values were calculated using (1) and (2) [5], [6].

$H_{o}=\left(\frac{24}{\pi}\right) I_{g s} f\left[\cos \lambda \cdot \cos \delta \cdot \sin w_{s}+\left(\frac{\pi}{180}\right) \cdot w_{s} \cdot \sin \lambda \cdot \sin \delta\right](1)$

$$
f=1+0.033\left(\operatorname{Cos} \frac{360 n}{365}\right)
$$

Declination angle $(\delta)$ and hour angle $\left(w_{s}\right)$ were calculated using following equations [5], [7]-[9].

$$
\begin{gathered}
\delta=23.45 \operatorname{Sin}\left(360 \frac{n+284}{365}\right) \\
w_{s}=\cos ^{-1}(-\tan \lambda \cdot \tan \delta)
\end{gathered}
$$

\section{B. Calculating of Average Daily Solar Radiation on a Horizontal Surface in Mersin City}

Modelling of global solar radiation on horizontal surfaces were performed using six models in the literature. These model's variables were $S / S_{0}$ and $w_{S} . S_{0}$ values were calculated using (5). Measured $S$ values were used in the models [5].

$$
s_{0}=\frac{2}{15} \cos ^{-1}(-\tan \lambda \cdot \tan \delta)
$$

\section{Model in Literature}

Model 1 (this model is modified Lewis model for Turkey Country) [10], [11];

$$
\frac{H}{H_{0}}=0.18+0.62\left(\frac{S}{S_{0}}\right)
$$

Model 2 [12];

$$
\frac{H}{H_{0}}=0.206+0.546\left(\frac{S}{S_{0}}\right)
$$

Model 3 [13];

$$
\frac{H}{H_{0}}=0.162802+0.780634\left(\frac{S}{S_{0}}\right)^{0.276845}
$$

Model 4 [14];

$$
\frac{H}{H_{0}}=0.006324^{(1 / s)}
$$

Model 5 (this model is modified Lewis model for Isparta City) [4];

$$
\frac{H}{H_{0}}=0.192888\left(\frac{s}{s_{0}}\right)+0.334576
$$

Model 6 (this model is developed for Turkey Country) [4];

$$
\frac{H}{H_{0}}=\left[\frac{1.333962\left(\frac{s}{s_{0}}\right)}{0.044188 . \omega_{s}}\right]+0.002578 . \omega_{s}
$$

\section{Statistical Parameters for Determining Success of Models}

MPE (Mean percentage error), MBE (Mean bias error) and 
RMSE (Root mean square error) were used for statistical analyses of models. The lowest error parameters show that high level accuracy for models [15].

$$
\begin{gathered}
M P E=\frac{1}{n} \sum_{i=1}^{n}\left(\frac{H_{i, \text { pred. }}-H_{i, \text { meas. }}}{H_{i, \text { meas. }}}\right) \times 100 \\
M B E=\frac{1}{n} \sum_{i=1}^{n}\left(H_{i, \text { pred. }}-H_{i, \text { meas. }}\right) \\
R M S E=\sqrt{\frac{1}{n} \sum_{i=1}^{n}\left(H_{i, \text { pred. }}-H_{i, \text { meas. }}\right)^{2}}
\end{gathered}
$$

\section{RESULT AND DISCUSSIONS}

Predicted and measured monthly $\mathrm{H}$ values of Mersin City were showed Fig. 2-Fig. 7. Model 1 developed by Tiris et al. [10] predicted higher values than measured $H$ values for summer months. But Model 1 predicted more accuracy values for winter months (Fig. 2 and Fig. 3).

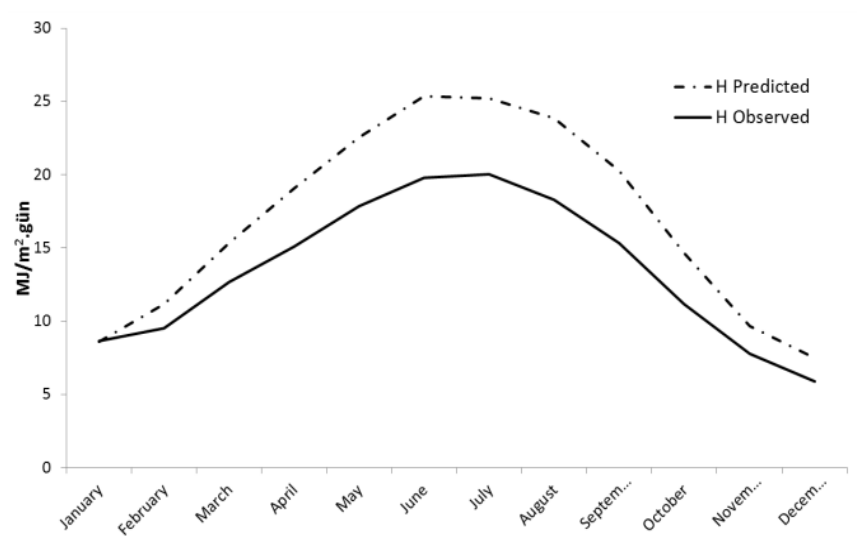

Fig. 2. Measured and predicted values by Model 1 .

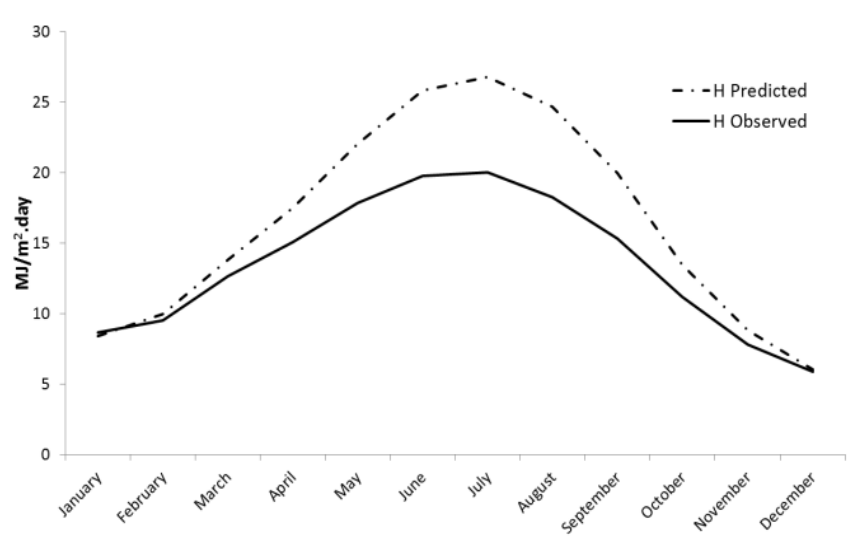

Fig. 3. Measured and predicted values by Model 2 .

The more accuracy values were predicted by Model 2 for winter months. In spring and autumn months Model 2 calculated more correctness values than Model 1. But accuracy of predicted values by Model 2 was high level in summer months (Fig. 3).

Model 3 similar to Model 2 and Model 1 predicted more correct values in winter than summer months (Fig. 4 and Fig. $5)$.

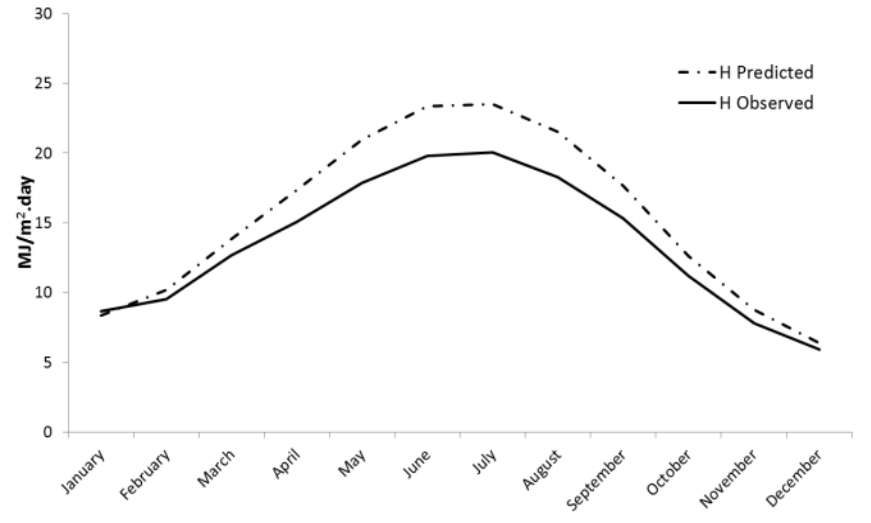

Fig. 4. Measured and predicted values by Model 3.

Distribution of predicted values by Model 4 were different from Model 3, 2, 1. Predicted values in November to in the middle of February were lower than measured $H$ values but in the other months these values were higher than measured $H$ values (Fig. 5).

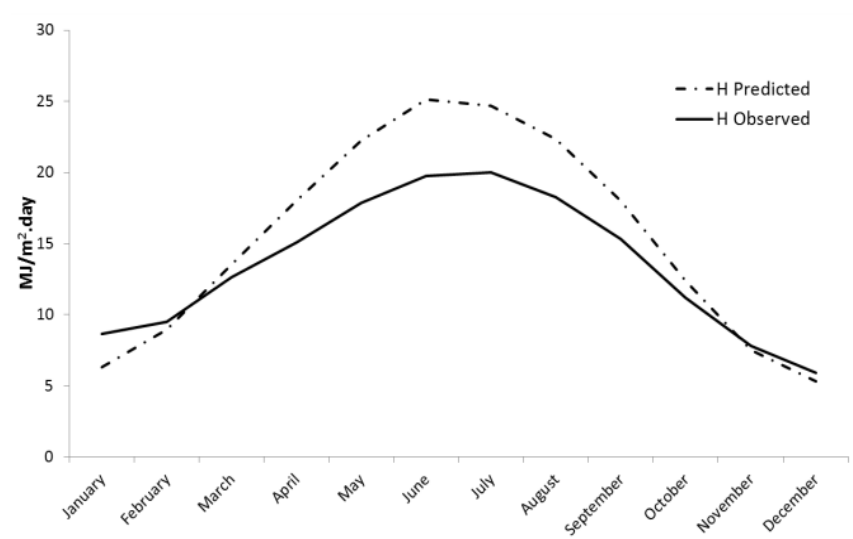

Fig. 5. Measured and predicted values by Model 4

Model 5 used $\mathrm{S} / \mathrm{S}_{0}$ variable parameters for modeling and in this model have two constant value. Model 5 gave successfully predicted values except from July, August, September, December and January months for Mersin City. But predicted values by Model 5 were more close to measured values than before models (Fig. 6).

Model 6 used $S / S_{0}, w_{s}$ and $\lambda$ variable parameters for modeling. Model 6 calculated lower $\mathrm{H}$ values than measured values for January, February and March. But, it calculated more accuracy values for the other 9 months (Fig. 7).

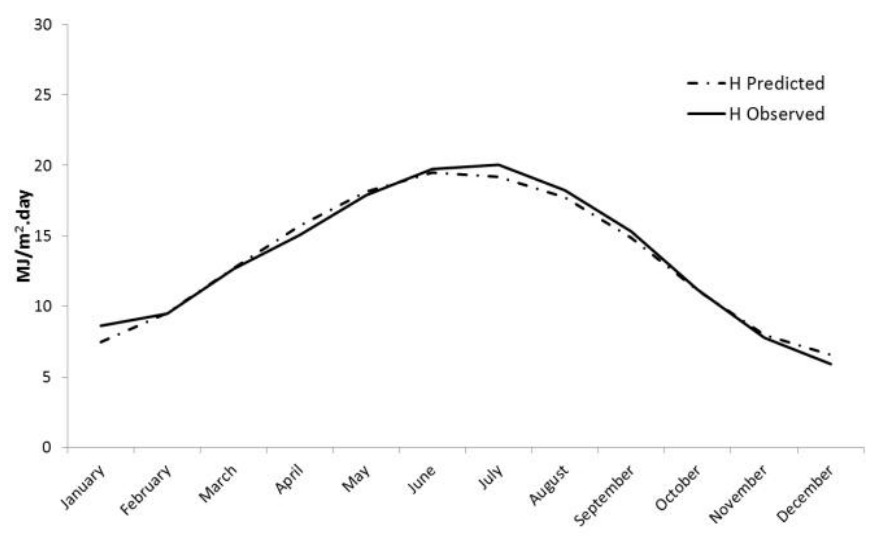

Fig. 6. Measured and predicted values by Model 5 . 


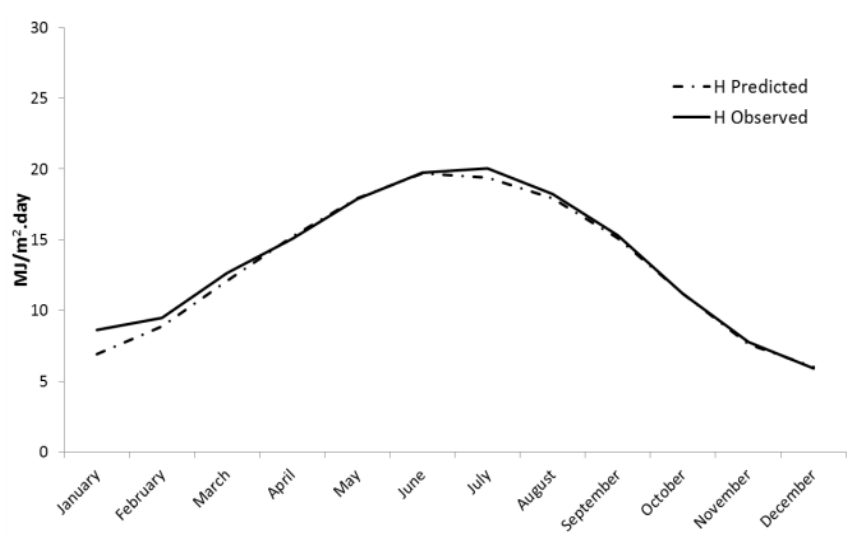

Fig. 7. Measured and predicted values by Model 6 .

Statistical analyses results were given in Table II. Absolute values of MPE and MBE parameters must be uses for assessment of the success of Model. Statistical analyses results showed that error values of Model 6 and Model 5 lower than other models.

\begin{tabular}{cccc}
\multicolumn{4}{c}{ TABLE II: STATISTICAL ANALYSES RESULT } \\
\hline \hline $\begin{array}{c}\text { Model } \\
\text { Number }\end{array}$ & $\begin{array}{c}\text { MPE } \\
\text { Mean percentage } \\
\text { error }\end{array}$ & $\begin{array}{c}\text { MBE } \\
\text { Mean bias } \\
\text { error }\end{array}$ & $\begin{array}{c}\text { RMSE } \\
\text { Root mean square } \\
\text { error }\end{array}$ \\
\hline Model 1 & 22.1937 & 3.5925 & 4.6346 \\
Model 2 & 17.9941 & 2.9347 & 3.8227 \\
Model 3 & 12.3544 & 1.8783 & 2.2542 \\
Model 4 & 4.6244 & 1.7345 & 3.7300 \\
Model 5 & 3.3294 & 0.6092 & 0.9810 \\
Model 6 & -4.7622 & -0.3251 & 0.8576 \\
\hline \hline
\end{tabular}

\section{SUMMARY}

In this study modeling of global solar radiation on horizontal surfaces for Mersin City using extraterrestrial radiation on a horizontal surface were evaluated. Six different models were used for this aim. Statistical analyses showed that accuracy of Model 6 is higher than other models for prediction of global solar radiation on horizontal surfaces for Mersin City.

\section{NOMENCLATURES}

$G_{s c}:$ Solar Constant $1367 \mathrm{~W} / \mathrm{m}^{2}$;

$H$ : Average daily solar radiation on a horizontal surface $\left(\mathrm{J} / \mathrm{m}^{2}\right.$.day);

$H_{0}$ : Monthly average daily extraterrestrial radiation on a horizontal surface $\left(\mathrm{J} / \mathrm{m}^{2}\right.$.day);

$H_{i, \text { meas }}$ : Measured $H$ value;

$H_{i, p r e d}$ : Predicted $H$ value;

$M B E$ : Mean Bias Error;

$M P E$; Mean Percentage Error;

$n$ : The number of the day of the year starting from the first of January;

RMSE: Root Mean Square Error;

$w_{s}$ : Hour angle;

$\delta$ : The Solar Declination; angle;

$\lambda$ : Latitude;

$S$ : Sunshine length $(h)$;

$S_{0}$ : Day length $(h)$.

\section{REFERENCES}

[1] Energy Report 2013, DEKTMK: World Energy Council Turkish National Committee, 2014.

[2] A. Demirbas and R. Bakis, "Energy from renewable sources in Turkey: Status and future direction," Energy Sources, vol. 26, no. 5, pp. 473-484, 2004.

[3] EIE: Renewable Enegy Agency. [Online]. Available: http://www.eie.gov.tr/yenilenebilir/gunes.aspx

[4] R. Kulcu, "Modelling of global solar radiation for Isparta," Journal of The Faculty of Agriculture, vol. 10-1, pp. 19-26, 2015.

[5] J. A. Duffie and W. A. Backman, Solar Engineering of Thermal Processes, 3rd ed. New York: John Wiley\& Son, 2006.

[6] O. Mengec, C. Ertekin, and M. H. Sonmete, "Evaluation of global solar radiation models for Konya, Turkey," Energy Conversion and Management, vol. 47, pp. 3149-3173, 2006.

[7] C. Ertekin and O. Yaldiz, "Comparison of some existing models for estimating global solar radiation for Antalya, Turkey," Energy Conversion \& Management, vol. 4, pp. 311-330, 2000.

[8] K. Bakirci, "Correlations for estimation of daily global solar radiation with hours of bright sunshine in Turkey," Energy, vol. 34, pp. 485-501, 2009.

[9] C. Ertekin, R. Kulcu, and F. Evrendilek, "Techno-economic analysis of solar water heating systems in Turkey," Sensors, vol. 8, pp. 1252-1277, 2008.

[10] G. Lewis, "Estimates of irradiance over Zimbabwe," Solar Energy, vol. 31, pp. 609-12, 1983.

[11] M. Tiris, C. Tiris, and Y. Erdalli, "Water heating systems by solar energy," Marmara Research Centre, Institute of Energy Systems and Environmental Research, Gebze, Kocaeli, Turkey, 1997.

[12] A. Louche, G. Notton, P. Poggi, and G. Simonnot, "Correlations for direct normal and global horizontal irradiation on a French Mediterranean site," Solar Energy, vol. 46, pp. 261-266, 1991.

[13] N. Elagib and M. G. Mansell, "New approaches for estimating global solar radiation across Sudan," Energy Conversation Management, vol. 41, pp. 419-434, 2000.

[14] M. El-Metwally, "Sunshine and global solar radiation estimation at different sites in Egypt," J. Atmos. Sol.-Terr. Phys., vol. 67, no. 14, pp. $1331-1342,2005$.

[15] S. F. Khahro et al., "Evaluation of solar energy resources by establishing empirical models for diffuse solar radiation on tilted surface and analysis for optimum tilt angle for a prospective location in southern region of Sindh, Pakistan," Electrical Power and Energy Systems, vol. 64, pp. 1073-1080, 2015.

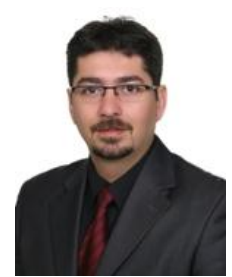

R. Kulcu was born in Çankırı, Turkey, in 1977. He received the B.Sc. degree from Trakya University in 1999 and the M.Sc. degree from Akdeniz University. He worked in Akdeniz University as a research assistant from 2000 to 2007 and received his Ph.D. degree.

His research interests are renewable energy source, composting systems and biogas technologies.

A. Suslu was born in Konya, Turkey, in 1985. He graduated from Suleyman Demirel University, Faculty of Agriculture in 2013, currently he is studying at the Graduate School of Natural and Applied Sciences, Department of Agricultural Machinery and Technology Engineering.

His research interests are development of automation software for agricultural process management.

C. Cihanalp was born in Antalya, in 1980. She graduated from Suleyman Demirel University, Faculty of Economics and Administrative Sciences in 2003. She worked in national education directorate from 2003 to 2007. She works in public institutions. She has done graduate studies in the Department of Economics in 2014. Currently, she is studying at the Graduate School of Natural and Applied Sciences, Department of Agricultural Machinery and Technologies.

D. Yılmaz was born in Antalya, in 1976. He graduated from Ankara Univesity, Faculty of Agriculture in 1999. He received his M.Sc., Ph.D degrees in Akdeniz University, from 2002 to 2008.

His research interest harvesting machinery, biological material properties, design and production of farm machines. 